\title{
PENANGANAN POLA PENGERINGAN MELALUI PENATAAN SISTEM DRAINASE STASIUN KAMPUNG BANDAN
}

\author{
Ir. Tri Yuli Andaru,M.Si \\ Dosen STTD \\ Jl. Raya Setu no.89 \\ Cibuntu - Cibitung \\ Tlp/Fax : ( 021 ) 8254640
}

\author{
Ir. Djoko Septanto,MM \\ Dosen STTD \\ J1. Raya Setu no.89 \\ Cibuntu - Cibitung \\ Tlp/Fax : ( 021 ) 8254640
}

\author{
Drs. Fauzi,MT \\ Dosen STTD \\ J1. Raya Setu no.89 \\ Cibuntu - Cibitung \\ Tlp/Fax : ( 021 ) 8254640
}

\author{
Tarli,MM \\ Dosen STTD \\ Jl. Raya Setu no.89 \\ Cibuntu - Cibitung \\ Tlp/Fax : ( 021 ) 8254640
}

\author{
Bardi,MM \\ Dosen STTD \\ Jl. Raya Setu no.89 \\ Cibuntu - Cibitung \\ Tlp/Fax : ( 021 ) 8254640
}

\begin{abstract}
Humans and all living things need water and water is a material that makes life happen on earth. But water can also be a very devastating disaster if not properly managed and structured. for example a group of people who do not obey government rules for example by changing the actual land use for the impregnation and / or the disposal of water but used for other functions eg by making the building so that it can block the flow of water so the water will widen where to find the place in gravity but when damaged by a facility then causes events that are terrible ie flood and or planning flood control facilities that are planned not perfectly eg dam damaged so as to cause flooding.
\end{abstract}

Keyword : flood, drainage, drying pattern

\begin{abstract}
ABSTRAKSI
Manusia dan seluruh mahluk hidup membutuhkan air dan air merupakan material yang membuat kehidupan terjadi di bumi namun demikian air juga dapat merupakan malapetaka yang sangat sangat dahsyat apabila tidak dikelola dengan baik dan terstruktur. contohnya sekelompok orang yang tidak mentaati aturan pemerintah misalnya dengan mengubah tata guna lahan yang sebenarnya untuk peresapan dan atau pembuangan air tetapi digunakan untuk fungsi lain misal dengan membuat bangunan sehingga dapat menghalangi aliran air sehingga air akan melebar kemana mana mencari tempat secara grafitasi namun apabila terbendung oleh suatu fasilitas maka menyebabkan peristiwa yang maha dasyat yaitu banjir dan atau pula perencanaan fasilitas pengendali banjir yang direncanakan tidak dengan sempurna misal bendungan yang jebol sehingga menyebabkan terjadinya banjir.
\end{abstract}

Kata kunci : Banjir, drainase, pola pengeringan 


\section{PE N D A H UL UA N}

\section{A. LATAR BELAKANG}

Seperti kita ketahui bersama di indonesia mempunyai musim penghujan dan kemarau sepanjang tahun ,dan jumlh air yang berada pada suatu wilayah tergantung dari curah hujan yang terjadi pada wilayah tersebut. Jumlah air pada musim penghujan tentu akan meningkat secara tajam dan air membutuhkan tempat untuk mengalirkan air dari hulu ke hilir dan apabila jalan air tersebut terhambat oleh suatu bangunan dan atau bangunan yang tidak stabil maka aliran air akan terganggu dan bahkan akan membuat bangunan yang tidak stabil tersebut akan runtuh diterjang oleh air selain itu .ada pula bangunan yang tidak sesua dengan peruntukan dan dibangun dengan tidak memperhatikan lingkungan sekitar juga akan menyebabkan terhambatnya aliran air dan air selalu akan mencari tempat yang lebih rendah ( grafitasi ) dan akan mengakibatkan air menjadi tergenang dan banjir

\section{B. IDENTIFIKASI MASALAH}

1. Terjadi keterlambatan perjalanan kereta api di emplasemen stasiun Kampung Bandan yang diakibatkan oleh tergenangnya sebagian rel oleh air hujan yang tidak dapat mengalir dengan sempurna kesaluran pembuangan yakni ke saluran primer sungai Gunung Sahari

2. Stasiun KP. Bandan merupakan sta.antara baik kearah manggarai terus ke depok dan bogor serta stasiun Jatinegara dan Bekasi ,stasiun tersebut juga merupakan stasiun antara untuk lintas jarak jauh dari arah sebelah timur jakarta

3. Apabila pada puncak musim hujan yang biasanya terjadi antara bulan pebruari sampai dengan maret pada stasiun KP. Bandan selalu tergenag air akibat saluran pembuangan yang tidak berfungsi dengan baik dan atau sungai gunung sahari yang tidak mampu menampung luapan air dari emplasemenT sehingga emplasemen stasiun KP.Bandan menjadi kubangan dan tergenang oleh air hujan tersebut.

4. Pola pengeringan emplasemen stasiun KP.Bandan dibuang secara hierarki melalui drainase mikro dilingkungan sekitar emplasement stasiun kemudian aliran diteruskan melalui saluran penangkap yaitu saluran primer Gunung Sahari namun yang terjadi adalah saluran primer tersebut tdk dapat menerima kiriman air dari emplasemen stasiun KP .Bandan hal ini dikarenakan tertutupnya air akibat bangunan sekitar yang lebih tinggi serta pendangkalan saluran gunung sahari sehingga luas penampang basah berkurang dan volume yang ditampung tdk optimal dan air kemabali dan mengakibatkan banjir pada simpul kereta api di st, KP Bandan tersebut

5. Keberadaan stasiun KP.Bandan tersebut sangat vital bagi lalu lintas perkeretaapian perkotaan dan antar kota antar propinsi mengingat stasiun tersebut merupakan stasiun operasi dan naik turun penumpang yang 
tentunya akan menghambat pula berbagai kegiatan seperti bisnis dan perkantoran serta wisata, budaya dan poltik.

\section{BATASAN MASALAH}

Dari hasil identifikasi masalah tersebut diatas dan terbatasnya waktu pelaksanaan survey serta dana yang tersedia, maka permasalahan dibatasi hanya pada peningkatan pelayanan melalui perencanaan pola pengeringan melalui heirarki saluran tertier - sekunder dan primer baik di internal dan eksternal stasiun KP.Bandan.Permasalahan yang akan dianalisis adalah hanya terkait dengan drainase baik diluar dan didalam emplasement serta tidak terkait dengan penataan bangunan disekitar namun peneliti hanya menyarankan bagaimana tata letak dan bangunan yang ideal apabila disekitar daerah tersebut terdapat fasilitas transportasi yang harus terbebab dari banjir karena dapat menyebabkan seluruh perjalanan kereta jarak pendek dan jauh serta perkotaan akan terganggu.

\section{PERUMUSAN MASALAH}

Dari batasanpermasalahan tersebut diatas maka agarpenyelesaian masalah tersebut dapat lebih mudah pemecahannya dan hasilnya terukur maka diperlukan perumusan masalah sebagai berikut:

Apakah dengan perencanaan pola pengeringan yang menyeluruh dapat menyelesaikan permasalahan banjir pada emplasemen stasiun kampung bandan ?

\section{ASPEK PUSTAKA}

1. Pengelolan sumber daya air terpadu

Pengelolaan sumber daya air terpadu merupakan sebuah buku karangan dari Robert J .Kodoatie .Ph.d dan Roestam Syarif Ph.d yang menulis tentang siklus hidrologi,sumber daya air dan permasalahan pengelolaaan sumber daya air serta sistem dan infrastruktur keairan yang meliputi sistem drainase,sistem aliran air ta ah,sistem pengelolaan konservasi air,sistem pengelolaan erosi dan sedimentasi.selain itu juga membahas tentang pengelolaan sumberdaya air terpadu,pengelolaan sumber daya air menurut undang undang keairan serta kebijakan sumber daya air untuk daerah otonom dan Nasional

2. Hidrologi teknik

Hidrologi teknik merupakan sebuah buku karangan ir. C.D. Soemarto .Dipl.HE yang banyak membahas tentangevaporasi dan evaprotranpirasi,infiltrasi dan perkolasi,unsusr unsur aliran sungai,hidrografi banjir,penelusuran banjir,penerapan statistik dalam 
hidrologi,air tanah hidrologi daerah pantai dan erosi serta sedimentasi ,dan juga membahas tentang model matematik dan simulasi hidrologi.

3. Drainase terapan

Drainase terapan merupakan sebuah buku karangan dari ir. H.A Halim Hasmar yang membahas drainase terapan yang meliputi aspek hidrologi yang terkait dengan siklus hidrologi dan karakteristik hujan,aspek hidrolika yang meliputialiran air pada saliran terbuka dan tertutup termasuk sifat dari aliran tersebut,perancangan sistem drainase yng meliputi pola arah aliran,situasi dan kondisi fisik kota serta langkah langkah perencanaannya,dan beberapa jenis dan macam drainase seperti drainase muka tanah ,drainase sunuran,drainase bawah muka tanah ,drainase gabungan dan drainase khusus.

\section{E T O D O L O G I PE N E L I TI A N}

\section{A. DESAIN PROSES PENELITIAN}

Lokasi kegiatan direncanakan diwilayah perkeretaapian di sekitar stasiun kampung bandan yang selanjutnya kegiatan ini direncanakan dibagi dalam empat (4) tahapan yang dimulai dari identifikasi masalah, pengumpulan data,pengolahan data dan keluaran ( output)

Dan secara rinci dapat dijelaskan sebagai berikut :

1. Identifikasi masalah

Pada tahapan ini akan didapat berbagai masalah dari wilayah studi yang selanjutnya untuk mempermudah penyelesaian penelitian dibuat perimusan masalah yang diambil dari batasan permasalahan yang akan diteliti.

2. Pengumpulan data.

Pengumpulan data ini meliputi pengumpulan data sekunder yang didapat dari instansi terkait seperti Dinas pengembangan sumber daya air , dinas pemukiman dan tata ruang DKI,Ditjen KA Kementrian Perhubungan dan PT KA Daop 1 Jakarta meliputi peta jaringan jalan, jaringan pelayanan angkutan ka perkotaan dan ka antar kota ,data pergerakan ka ,data sarana dan prasarana ka termasuk Sintellist, Gapeka,nama No ka yang beroperasi ,data stam formasidan sistem operasi yang digunakan.

Data primer diambil dari hasil survey yang meliputi survey inventarisasi jalan dan jembatan ka diemplasemen stasiun tanah abang ,perlintasan sebidang ka,data sintellist,stasiunantara dan stasiun OD ,daerah padat penduduk,survey wawancara terhadap masyarakat disekitar jalur ka .

3. Setelah dilakukan pengumpulan data maka dilakukan analisis guna mendapatkan kondisi yang sebenarnya ada dilapangan untuk petakan sehingga mudah untuk pengawasan,perbaikan dan perawatan dari emplasemen stasiun ka tersebut.

4. Keluaran (output) 
Pada tahap ini merupakan tahap akhir yang meliputi tindak lanjut Dari hasil analisa data yang selanjutnya dituangkan dalam bentuk kesimpulan ,saran dan rekomendasi yang tergambar dalam penanganan pola pengeringan emplasemen stasiun kampung bandan jakarta utaraa dan sekitarnya

\section{ANALISA DAN PEMECAHAN MASALAH}

\section{A. ANALISA PENANGANAN BANJIR}

\section{ANALISA PENYEBAB BANJIR}

Genangan air yang mengakibatkan banjir pada suatu daerah biasanya diakibatkan oleh perubahan akibat penyalahgunaan tata guna lahan di daerah aliran sungai ( DAS ),pembuangan sampah ,erosi dan sedimentasi,kawasan kumuh disepanjang bantaran sungai dan drainase,perencanaan pengendalian banjir yang belum tepat,curah hujan yang tinggi,pengaruh geofisik dan fisiografi sungai,kapasitas sungai dan drainase yang kurang memadai,pengaruh air pasang ROB,penurunan tanah,drainase tersumbat dan kerusakan bangunan pengendali banjir .sedang genangan air yang mengakibatkan banjir di kawasan stasiun kampung bandan dapat dijelaskan sebagai berikut :

a. Aspek tata guna lahan

Penggunaan tanah dalam ruang dikawasan sekitar mangga dua gunung sahari - stasiun kampung bandan sampai dengan Ancol.

Penggunaan ruang dalam lahan tanah pada lokasi survey yakni disekitar kawasan mangga dua - gunung sahari - kampung bandan sampai dengan ancol dengan luas sekitar 600 hektar dan atau dengan lebar $20 \mathrm{~km}$ serta sepanjang10 km keselatan dan kearah utara sampai dengan muara sungai gunungsahari di pantai utara jawa terdapat berbagai penggunaan ruang dari lahan tanah seperti untuk kawasan perdagangan yakni beberapa hotel seperti hotel dan apartemen Novotel serta beberpa Mall seperti Mall mangga dua square dan Mall mangga dua dengan elevasi beda tinggi permukaan ruang sekitar antara $107 \mathrm{~cm}$ sampai dengan $125 \mathrm{~cm}$ dan kawasan pemukiman padat penduduk dengan berbagai kegitan seperti perkantoran baik swasta maupun pemerintah, rumah makan, warung makan .kios ,rumah kost dan sekolahan yang membuat keberadaan stasiun kampung bandan menjadi sebuah danau yang pada musim penghujan tinggi ditengarai sebagai tempat penampungan air / banjir hal ini diakibatkan oleh fasilitas penunjang drainase perkotaan seperti saluran primer Gunung Sahari yang mengalami pendangkalan tiap tahunnya sehingga perlu perawatan melalui dredging agar dapat mempertahankan luas dan volume dari penampang basah yang sesuai 
dengan kebutuhan untuk menampung debit air akibat banjir 50 tahunan ( Q 50 ) sehingga dapat menampung curah hujan yang tinggi . seperti yang telah kita ketahui saat ini bahwa saluran primer Gunung Sahari yang hilirnya bermuara di pantai utara jakarta serta saluran sekunder dan tersier dengan kondisi yang ada pada saat ini masih terdapat kendala yakni terhambatnya aliran air oleh tumpukan sampah akibat dari lemahnya disiplin masyarakat sekitar kawasan tersebut dalam membuang sampah.

dapat dijelaskan bahwa khusus lahan dikawasan sekitar stasiun KP. Bandan dikelilingi oleh kawasan pemukiman padat penduduk dengan perkiraan seluas $400 \mathrm{~km}^{2}$ yang dikelilingi oleh lalan arteri primer dan jalan penghubung dengan panjang sekitar $12 \mathrm{~km}$ dengan lebar $24 \mathrm{~m}$ untuk arteri primer dan 8-10 m untuk jalan penghubung serta bangunan bangunan super blok yang diantaranya seperti mall mangga dua square dan mall mangga dua dan beberapa hotel high rise bulding serta beberapa apartemen yang diantaranya kawasan hotel dan apartemen Novotel yang dimana letak bangunan tersebut mempunyai elevasi permukaan tanah dari kedudukan bangunan yang lebih tinggi sekitar 75 - $125 \mathrm{~cm}$ dari stasiun KA.kampung bandan sehingga menyebabkan stasiun KP Bandan seperti waduk yang tidak direncanakan dan apabila terjadi curah hujan yang sangat tinggi dengan intensitas hampir $1255 \mathrm{~mm}$ per jam pada bulan pebruari 2015 ST. Kampung bandan lumpuh total dan ini menyebabkan kerugian yang sangat besar bagi pengguna dan penyedia jasa transportasi jalan rel.

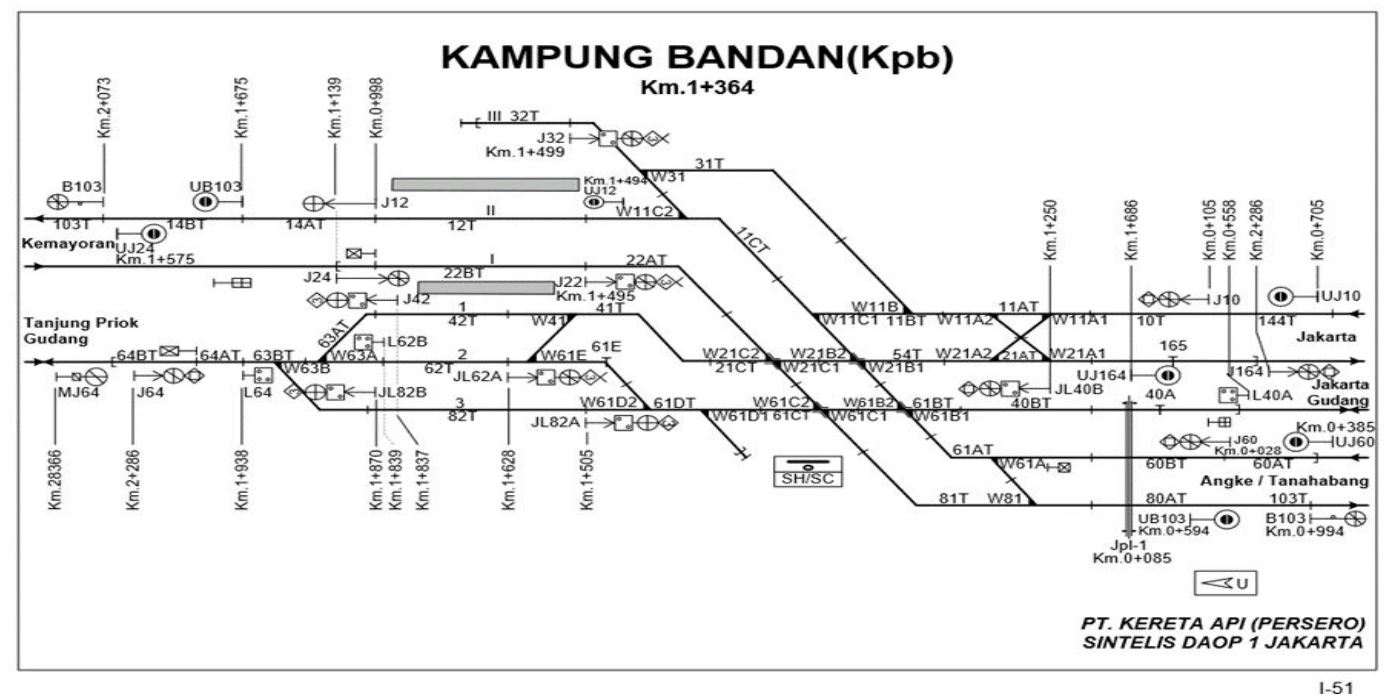

Gambar 1b

Penyebab banjir paling dominan 


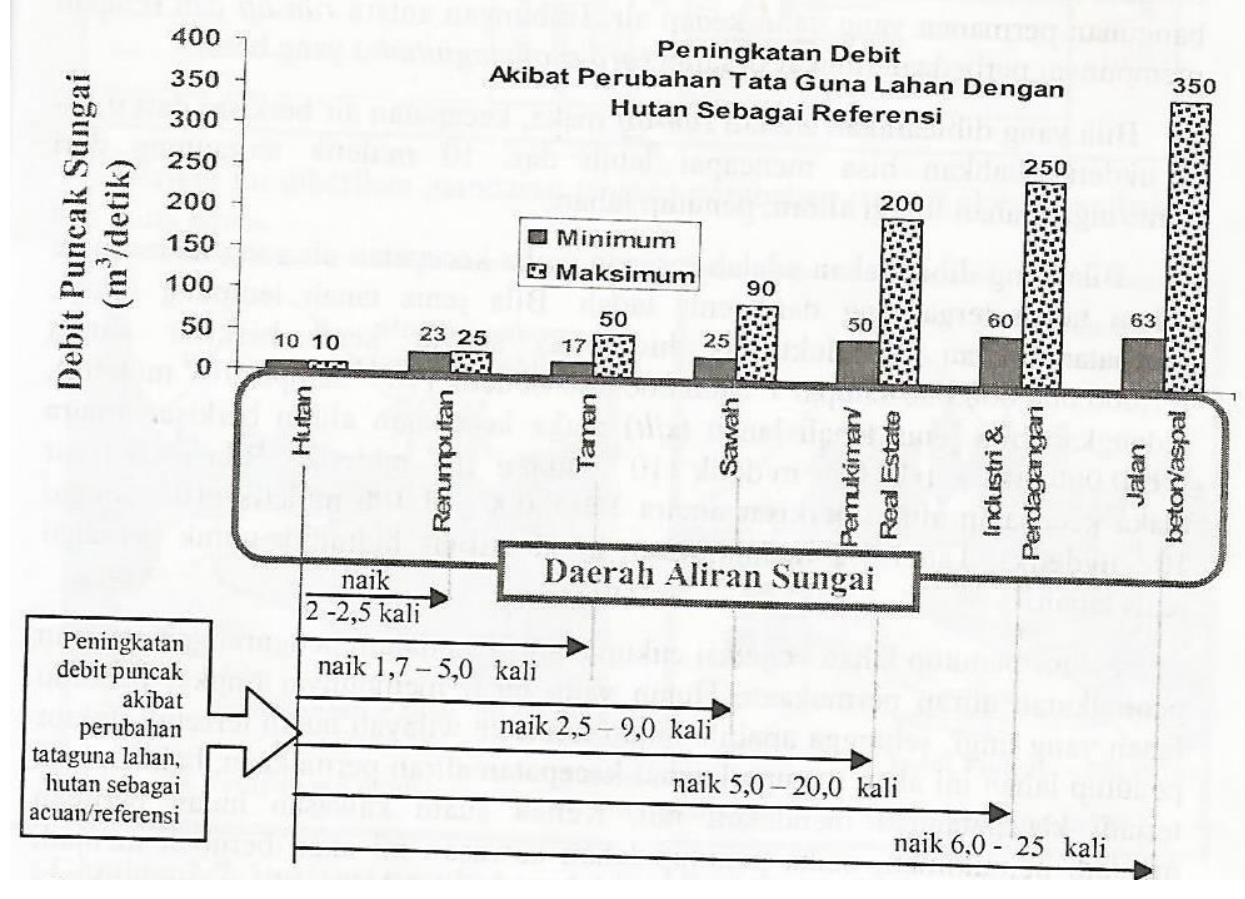

Jalur ka kampung bandan terendam air

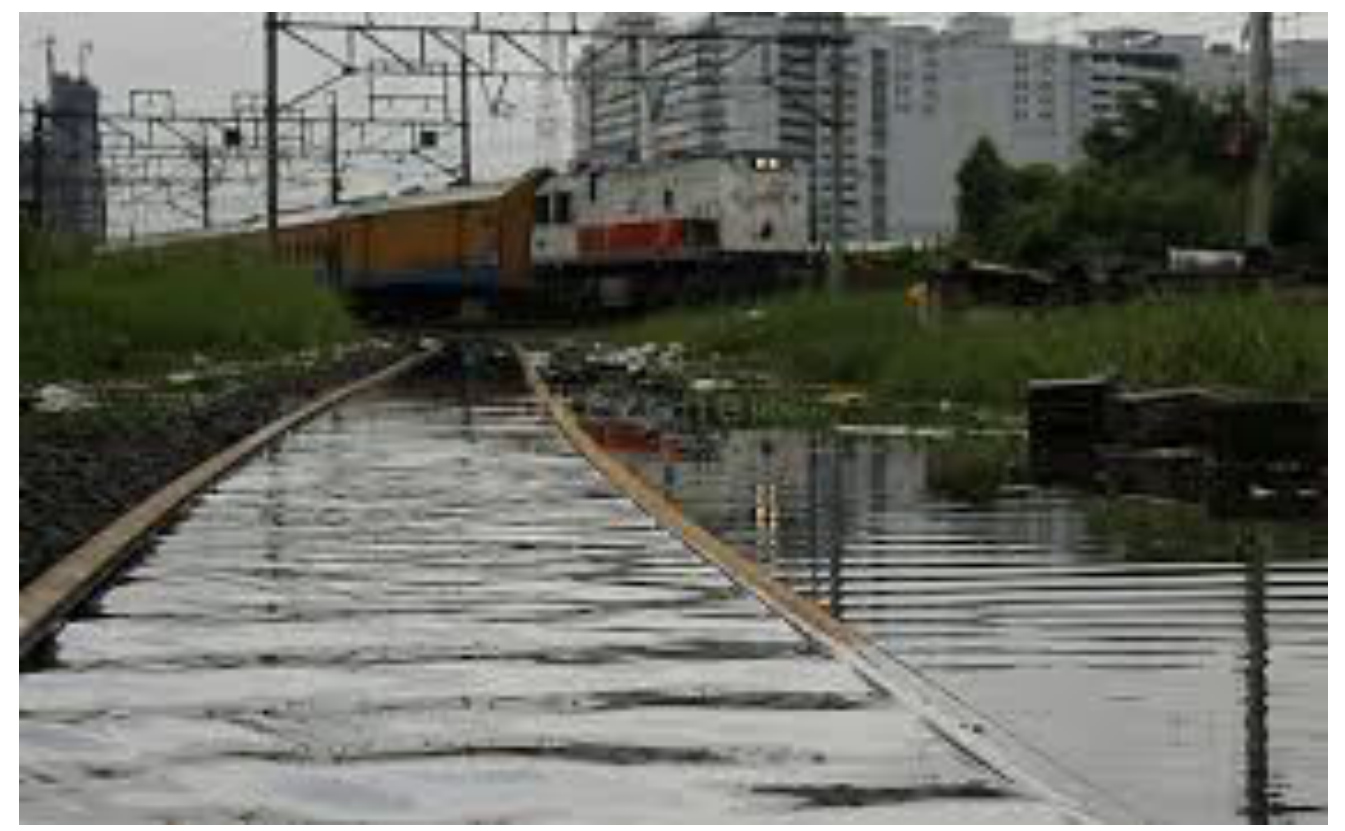

Gambar 7

Stasiun kampung bandan dari udara dalam posisi kering 


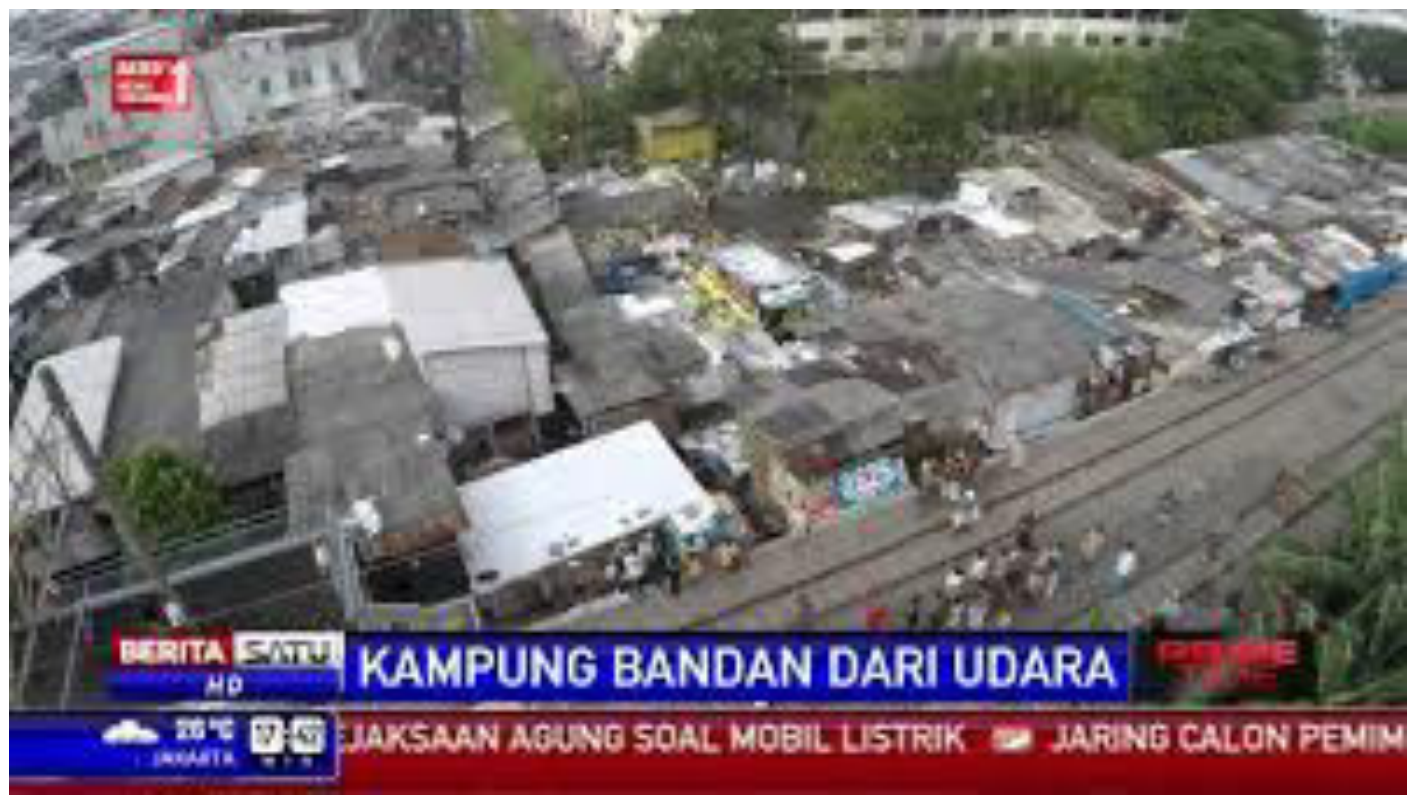

\section{B. ANALISA PENANGANAN POLA PENGERINGAN}

\section{ANALISA FUNGSI DAN SISTEM DRAINASE}

a) ANALISA FUNGSI DRAINASE.

Analisa Fungsi drainase didalam dan diluar emplasement yakni kawasan senen -mangga besar gunung sahari sampai dengan ancol adalah Fungsi dari suatu drainase yang secara teknis sangat penting untuk membebaskan suatu kawasan ruang dari wilayah emplasement stasiun kampung bandan dan kawasan di sekitarnya dari banjir akibatnya adanya genangan air terutama pada saat curah hujan tinggi dan rob yang naik ke permukaan tanah akibat adanya pasang air laut yang maksimum, sementra itu bila kita melihat kondisi eksisting dari drainase yang ada di dalam emplasement tersebut kurang memadai dan ditambah dengan ketidak sinerjian antar sistem drainase yang ada maka emplasement stasiun kampung bandan dan daerah kawasan mangga dua gunung sahari sering terjadi banjir dengan ketinggian antara 50 sampai dengan $150 \mathrm{~cm}$ pada saat curah hujan tinggi sehingga menghambat kelancaran angkutan kereta apidan jalan

\section{b) ANALISA SISTEM DRAINASE}

Analisa sistem drainase didalam dan diluar emplasement stasiun kampung bandanSeperti kita ketahui bersama bahwa sistem jaringan drainase terdiri dari drainase mayor dan minor yang yang artinya adalah untuk drainase mayor adalah sistem saluran air yang menampung dan mengalirkan air dari suatu daerah tangkapan air hujan ( catcment area ) dalam skala yang besar 
seperti saluran drainase primer yang dalam hal ini adalah saluran primer gunung sahari yang dimana saluran tersebut juga berfungsi sebagai saluran penghubung antara drainase yang ada disekitar kawasan yang dimana air dari drainase minor dibuang ke sungai gunung sahari t sehingga saluran tersebut juga dinamakan saluran pembuang utama untuk selanjutnya dibuang kelaut sementara itu perlu diketahui pula bahwa saluran Gunung Sahari sangatlah penting karena berfungsi untuk mengeringkan wilayah dan kawasan senen - mangga dua - gunung sahari dan sekitar kampung bandan sedang drainase minor adalah sistem saluran air untuk menampung dan mengalirkan air dari kawasan CBD / bisnis ,kawasan padat penduduk Serta simpul yang dalam hal ini adalah stasiun kampung bandan sehingga kawasan tersebut terbebas dai genangan air akibat banjir.untuk memperjelas manajemen rekayasa dari sistem drainase dapat dijelaskan melalui gambar tersebut dibawah ini :

\section{Gambar 16}

\section{Manajemen dan rekayasa sistem drainase perkotaan}

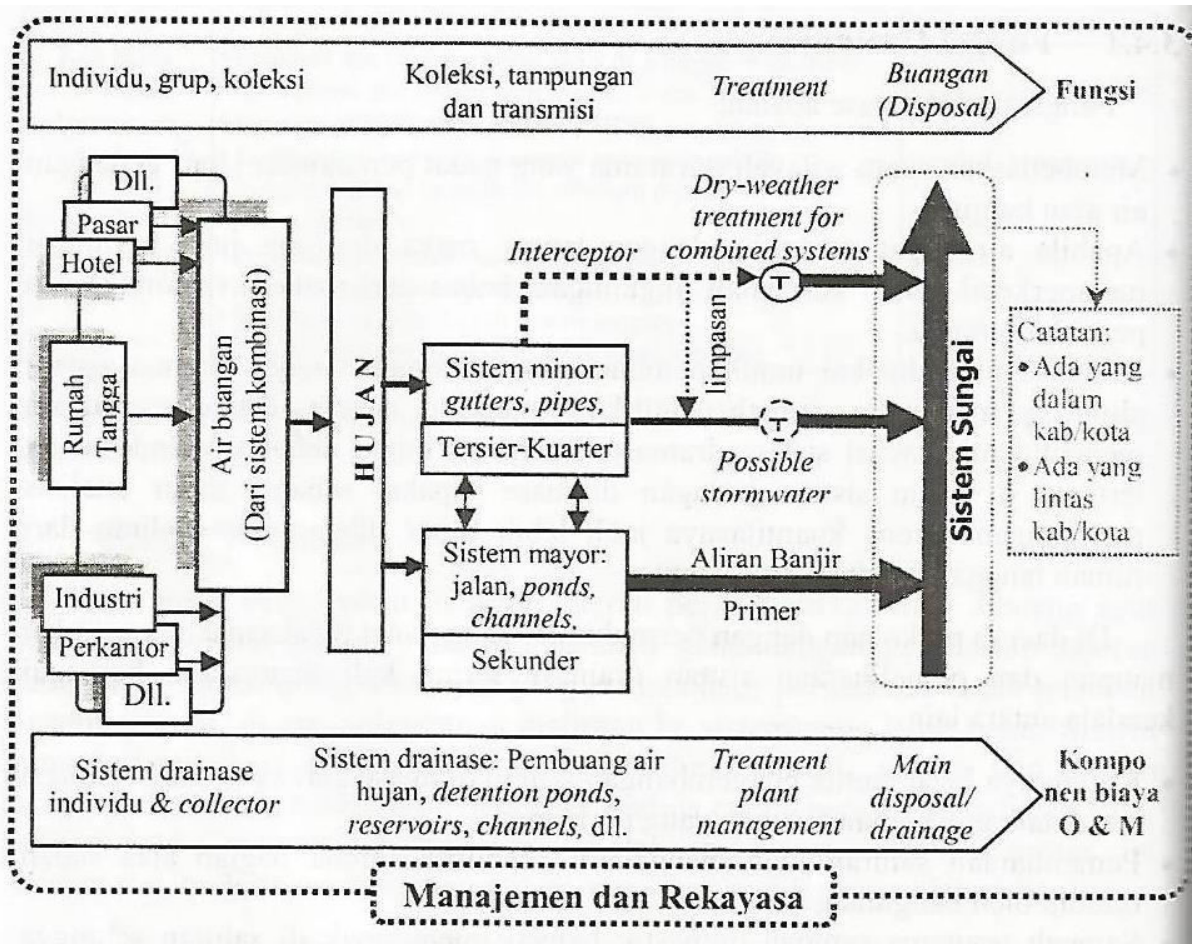

a) ANALISA PENATAAN SISTEM DRAINASE

\section{a. Analisa sistem drainase terpadu antar kawasan didalam dan diluar empalasement stsasiun kampung bandan}


Sistem drainase yang berada pada kawasan mangga dua- gunung sahari -kp.bandan sampai dengan ancol harus dievaluasi yang kemudian direncanakan secara sinergi dan terpadu sehingga aliran air dapat berjalan sesuai hirarki yakni dari tertiermenuju sekunder dan akhirnya di buang ke saluran mayor gunung sahari dan selanjutnya diteruskan kelaut dengan waktu yang tidak terlalu lama yakni $<0.15$ jam

b. Penataan sistem drainase didalam emplasement Stasiun KP. BANDAN

Sistem drainase didalam emplasement stasiun kampung bandan belum Dapat menampung limpasan air didalam stasiunhal ini terlihat dari kondisi saluran drainase mikro tertier terbuka diujung peron dan tertutup dibawah peron sepanjang lebih kurang 1200 meter di bagian kiri dan kanan dengan dimensi lebar saluran tinggi $35 \mathrm{~cm}$ dan lebar 30 cmsehingga sangat sulit untuk menampung air hujan dengan curah hujan yang sangat tinggi, dan seperti yang terjadi pada bulan pebruari 2015 tasiu KP.BANDAN tenggelam dengan kedalaman air sekitar 18 $-30 \mathrm{~cm}$ sehingga se;uruh kereta baik KRL dan KA jarak jauh tidak dapat beroperasi.oleh karena itu supaya kejadian hal tersebut tidak terulang kembali perlu dilkukan penataan ulang melalui peninggian badan jalan rel lebih kurang 60 - $90 \mathrm{~cm}$ yang disertai tentunya dengan peninggian jembatan arah jakarta kota - ancol - tanjung priuk yang selanjutnya dibuat propil dari suatu sitem drainase dengan lebar $60 \mathrm{~cm}$ dan tinggi $80 \mathrm{~cm}$ yang disertai dengan pembuatan poulder disekitar kawasan kampung bandan sehingga air dapat dialikan terlebih dahulu ke poulder untuk selanjutnya dibuang melalui saluran sekunder ke saluran mayor gunung sahari dan untuk seterusnya dibuang ke laut lepas.

c. Penataan sistem drainase diluar emplasemen stasiun KP. Bandan

Untuk mengantisipasi banjir 50 tahunan serta dengan adanya peninggian badan jalan arteri primer dalam kota di kawasan gunung sahari arah ancol dan rencana peninggian badan jalan gunung sahari arah senen maka untuk menghindari stasiun kp.bandan dari genangan air yang dapat mengakibatkan banjir sangat perlu dilakukan pembuatan poulder disekitar kawasan stasiun kampung bandan seoerti yang tekah dijelaskan tersebut diatas sedang peninggian tanggul sungai gunung sahari juga harus dilakukan palin tidak setinggi satu meter, walupun pada saat ini sungai mayor tersebut telah ditinggikan setinggi dua meter karena jika dilakukan dredging akan membutuhkan biaya mahal karena harus dilakukan dua kalidalam setahun mengingat Berikut disampaikan gambar rencana untuk penanganan sungai mayor gunung sahari yang telah mengalami pendangkalan akibat sedimen transport . 


\section{Gambar 18}

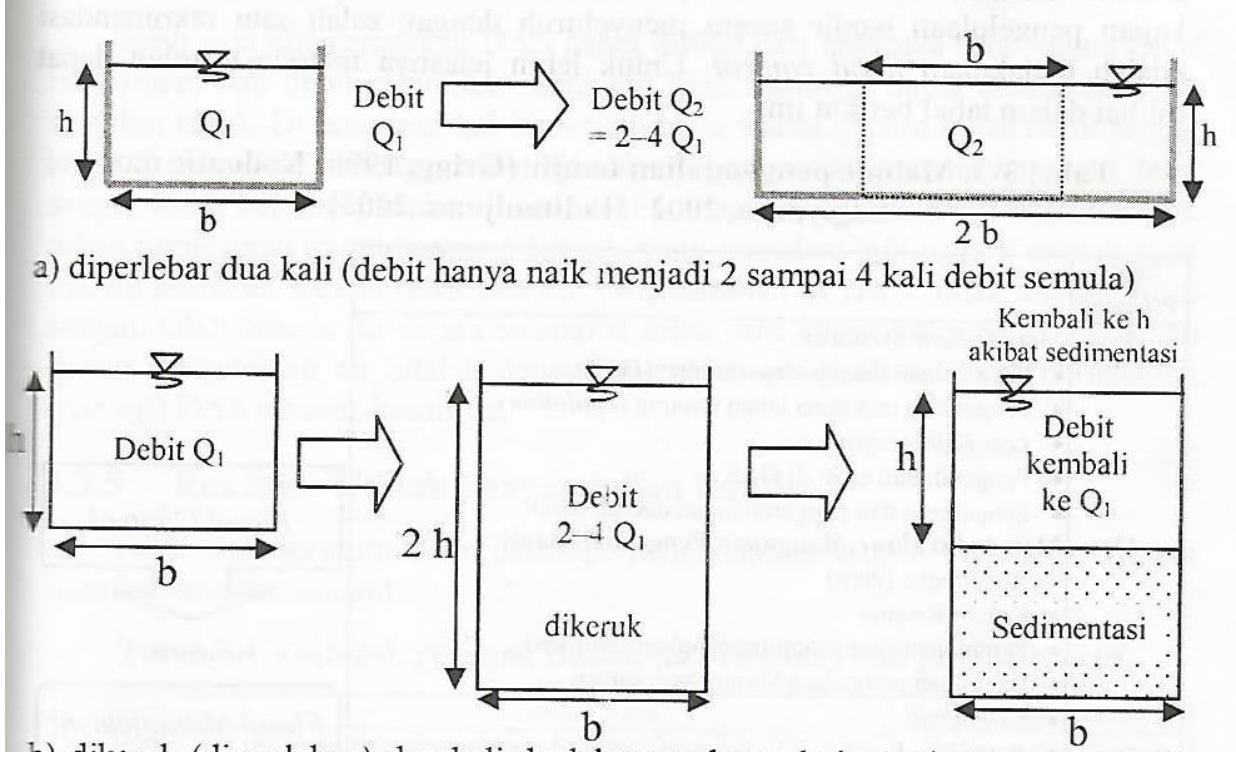

\section{KESIMPULAN DAN SARAN}

\section{A. KESIMPULAN}

Dari hasil survey lapangan yakni dikawasan sekitar stasiun kampung bandan - gunung ahari -ancol dan pengolahan data melalui instrumen dan simulasi hidrologi serta pembahasan antar individu pada kelompok penelitian ini maka dapat ditarik kesimpulan sebagai berikut :

1. Dilihat dari sisi rencana umum tata ruang wilayah untuk jakarta utara khususnya kawasan stasiun kampung bandan dan sekitarnya masih banyak pelanggaran tata guna lahan yakni penggunaan ruang yang belum sesuai dan ketinggian peil permukaan tanah yang tidak beraturan dan menyebabkan stasiun kampung bandan tenggelam selain itu kegiatan sumber daya manusia disekitar kawasan khususnya yang padat dengan penduduk pengawasan masih rendah hal ini terlihat dari masih belum disiplinnya masyarakat sekitar dalam hal pembuangan sampah .

2. Dilihat dari aspek iklim/cuaca yang terkait dengan curah hujan untuk kawasan mangga dua - gunung sahari sampai dengan kawasan ancol jakarta utara terdapat cuaca yang cukup ekstrim dengan curah hujan yang tingggi terutama dari tahun 2007 sampai dengan 2010 yakni sekitar 12500 mm per detik dan pada tahun 2008 sampai dengan 2016 yakni sekitar 11250 mmper detik pada bulan antara desember - januari yang 
menyebabkan terjadinya genangan air disekitar jalan arteri primer gunung sahari antara titik didepan mangga dua square sampai dengan kawasan ancol akibat air yang tidak dapat mengalir dengan sempurna sesuai kaidah gravitasi dan perbedaan ketinggian permukaan tanah yang tidak merata yakni sekitar $75-150 \mathrm{~cm}$

3. Aspek non struktur

Belum optimalnya sosialisasi kepada masyarakat khususnya pada daerah kawasan padat penuduk mengenai pentingnuya fungsi dari drainase khususnya drainase MIKRO serta lemahnya pengawasan dalam mendirikan bangunan pada kawasan padat penduduk sehingga ruang dari lahan tanah yang seharusnya untuk aliran air digunakan penduduk untuk mmperluas dan atau membangun bangunan baru .

4. Aspek struktur

bangunan struktur pengendali banjir dikawasan mangga dua gunung sahari - KP.Bandan sampai dengan Ancol untuk sungai mayor sudah cukup baik yakni dengan adanya program pengerukan/dredging serta peninggian tanggul setinggi dua meter namun demikian dengan adanya peninggian badan jalan gunung sahari kearah ancol yang sekarang sudah ada dan rencana peninggian badan jalan gunung sahari kearah senen menyebabkan banjir kawasan tersebut tidak terhindarkan sbagai contoh pada bulan pebruari 2017 twerjadi genangan air setinggi hampr 75 - 100 cm sedang kondisi drainase yang tersedia di st. Kp.bandan juga sangat buruk yakni hanya mempunyai saluran dikanan dan dikiri sepur dengan ukuran lebar $30 \mathrm{~cm}$ dan kedalaman saluran tidak lebih dari $35 \mathrm{~cm}$ oleh karena itu disamping letak stasiun yang sangat rendah bila dibanding dengan bangunan sekelilingnya juga drainase tersebut tidak dapat berfungsi dengan optimal.

\section{B. SARAN}

1. Evaluasi kawasan peruntukan ruang dan wilayah

Perlu dilkukan evaluasi penataan dalam rangka peruntukan ruang dan wilayah sehingga didapat sinergi yang komprehensive antar bangunan struktur yang satu dengan yang lainya dengan selalu memeperhatikan kebutuhan masing masing untuk memelihara lingkungannya khususnya dalam penanganan banjir sehingga pola pengeringan pada masing masing ruang dalam wilayah dapat dikendalikan secara bersama dengan memperhatikan tidak saling mengganggu melainkan saling bersinergi sehingga permasalahan khususnya dlam penanganan pola pengeringan di masing masing ruang dalam wilayah tersebut dapat teratasi dengan baik 
2. Perencanan dan pengembangan kawasan

Apabila pada daerah kawasan sekitar sta. KP BANDAN akan terjadi perubahan fisik bangunan dan atau penambahan bangunan baru maka harus menyesuaikan dengan peraturan rencana umum tata ruang wilayah yang ada dan harus saling bersinergi .Selain itu apabila debit air yang ada telah mencapai titik tertinggi perlu dilakukan penghitungan ulang mengenai waktu konsentrasi serta mempertimbangkan adanya perbaikan serta penambahan bangunan struktur baru untuk pengendali banjir baik berupa kolam retentian dan atau perbaikan saluran mayor dan minor.

3. Pengaturan dan Penataan bangunan struktur

a. Perencanaan bangunan strukturseperti bangunan gedung yang bersifat bisnis yang dilanjutkan dengan pembangunan dan perbaikan serta pemeliharaan bangunan struktur tersebut harus direncanakan pula untuk bangunan struktur pengendali banjir. hal tersebut harus dilaksanakan secara menyeluruh dan saling tidak mengganggu yang dalam hal ini artinya adalah agar apabila terjadi hujan yang cukup tinggi semua aliran air dari masing masing bangunan dapat cepat mengalir ke laut lepas melalui saluran tertier dimasing masing ruang dan diteruskan ke saluran minor dan mayor dalam waktu yang tidak terlalu lama $\quad<0.15$

b. Sedang Pemeliharaan yang terkait dengan dredging dapat dikoordinasikan dengan pemerintah propinsi melalui pemerintah kota jakarta utara dan stke holder lainnya seperti PT. jaya ancol dan penegelola kawasan bisnis terkait untuk membahas segala permasalahan yang terkait dengan dredging mulai dari survay awal prederedge sounding sampai dengan pelaksanaan dredging selesa ( final sounding ).

c.

4. Pengaturan dan pengawasan non struktur terkait dengan kegiatan penduduk

Pengaturan dan pengawasan disekitar kawasan mannga dua - gunung sahari - kp bandan sampai dengan kawasan ancol untuk

Segala kegiatan non struktur harus dilakukan secara berkesinambungan dan terus menerus dan hal ini sangat pentinguntuk dilakukan karenanantinya disamping lingkungan akan menjadi bersih dan tertata dengan baik sementara itu penduduk juga dibiasakan untuk selalu berdisiplin untuk mengelola dan mengawasi lingungannya, sehingga kawasan ruang dan wilayah tersebut menjadi bersih dari tumpukan sampah sehingga air dapat mengalir dengan lancar sampai ke laut lepas. 


\section{DAFTAR PUSTAKA}

Undang-Undang Republik Indonesia No. 23 Tahun 2007 Tentang Perkeretaapian , Peraturan Pemerintah Republik Indonesia nomor 56 Tahun 2009 Tentang Penyelenggaraan Perkeretaapian

, Peraturan Pemerintah Republik Indonesia nomor 72 Tahun 2009 Tentang Lalu Lintas Kereta api , Peraturan Pemerintah Republik Indonesia nomor 47 Tahun 2014 Tentang standar pelayanan minimum untuk angkutan orang dengan kereta api 